\title{
Single phase shunt active power filter with simplified ADALINE neural network
}

\begin{abstract}
Shunt active power filter is known as powerful tool to compensate current harmonics. Previous development of its controller was by using modified ADALINE algorithm for harmonics extraction, which somehow still having complex features. Therefore, this paper presents three major improvements to the algorithm in related to sine and cosine vectors, weight updating algorithm, and average square error. The proposed algorithm is designed and developed in shunt APF's controller, and the shunt APF is simulated in MATLAB/Simulink. The simulation results show significant improvement as compared to the previous algorithm.
\end{abstract}

Keyword: Active power filter; ADALINE; Artificial neural network; Power quality; Harmonics 